\title{
Comparison of the Kelly's plication and TOT simultaneously with vaginal hysterectomy, on the incontinence, and sexual functions
}

\author{
Neslihan Bayramoglu Tepe ${ }^{1}$, Omer Bayrak ${ }^{2}$, Huseyin Caglayan Ozcan ${ }^{1}$, Mete Gurol Ugur ${ }^{1}$, Ilker Seckiner ${ }^{2}$ \\ ${ }^{1}$ Department of Obstetrics and Gynecology, University of Gaziantep, Gaziantep, Turkey; ${ }^{2}$ Department of \\ Urology, University of Gaziantep, Gaziantep, Turkey
}

\section{ABSTRACT}

Purpose: To compare the effect of vaginal hysterectomy-anterior/posterior colporrhaphy with Kelly's plication(VH-KP), versus vaginal hysterectomy-anterior/posterior colporrhaphy-transobturator tape(VH-TOT) surgeries on incontinence, quality of life, and sexual functions in patients with pelvic organ prolapse(POP), and concurrent obvious stress urinary incontinence(SUI).

Materials and Methods: Between 2013 and 2017, fifty patients treated with VH-KP(n = 25), and VH-TOT(n = 25) due to POP and SUI, were evaluated prospective consecutively.Age, parity, duration of urinary incontinence,and the daily pad use were recorded. Patients were filled "rinary Distress Inventory-6(UDI-6)", "Incontinence Impact Questionnaire 7(IIQ-7)" and "Index of Female Sexual Function(IFSI)" questionnaire forms at preoperatively,and postoperative 6th month. No usage of pads was accepted as subjective cure rate.Intraoperative, and postoperative complications were noted.

Results: There was no statistically significant difference between two groups, for the mean age of the patients, parity, duration of SUI, and the daily pad use, preoperatively ( $p$ > 0.05). Decreased UDI-6 scores, IIQ-7 scores and daily pad usage, and increased IFSF scores were found statistical significantly in each group, at the postoperative 6 th month $(\mathrm{p}<0.05)$. However, VH-TOT group had higher improvement rates, on UDI6 scores (69.5\% vs $63.0 \%, p=0.04)$. In addition, it was notable that the the rates of the patients had IFSF scores $\geq 25$ was higher in VH-KP group ( $p=0.05)$. Four $(16 \%)$ patients had recurrent SUI in the VH-KP group $(p=0.039)$ and vaginal extrusion occurred in $2(8 \%)$ patients in the VH-TOT group $(p=0.153)$, postoperatively.

Conclusions: Although the effects of VH-TOT surgery are superior to conventional methods for incontinence and quality of life; negative effects on sexual functions are notable. In addition, although recurrence rates of TOT are low, complications such as vaginal extrusion are accompanied by drawbacks of mesh usage.

\section{ARTICLE INFO}

\section{Keywords:}

Pelvic Organ Prolapse; Urinary

Incontinence; Quality of Life

Int Braz J Urol. 2018; 44: 779-84

\section{Submitted for publication:}

January 11, 2018

Accepted after revision:

April 04, 2018

Published as Ahead of Print:

May 05, 2018

\section{INTRODUCTION}

Pelvic organ prolapse (POP) is a common problem that occurs in half of multiparous women, and surgical treatment is required in one tenth of the patients (1-4). Accompanying urinary incontinence with symptomatic POP may affect sexual functions, may cause a decrease in self-confidence, and may 
lead to a poor relationship with the opposite gender (5) Some (11-45\%) of the women with urinary incontinence may avoid sexual intercourse due to the fear of urinary incontinence (6-9).

Surgery of POP and stress urinary incontinence (SUI) enables the resolution of dysfunctions and helps to provide anatomic balance of organs. Although surgical success is aimed for anatomic recovery, subjective functional results, cosmetic appearance, quality of life, and sexual functions are required to be evaluated all together (6-9). SUI accompanying POP may be treated using conventional methods or other methods that require the use of mesh, such as the mid-urethral slings (MUS). Anterior / posterior colporrhaphy with Kelly's plication (CA-KP) is one of the conventional methods performed in the treatment of SUI. Although it is an old method and the success rate is lower in the long term, it has been a popular method in some clinics among gynecologists and urologists (10). However, after the description of transoburator tape (TOT) procedure in the treatment of SUI in 2001 by Delorme, TOT has been the gold standard in many centers as a minimally invasive method (11).

The number of studies comparing the different surgical techniques in POP accompanying SUI, and simultaneously investigating the effect of these surgical procedures on sexual functions are limited in the literature. We aimed to compare the effect of vaginal hysterectomy-anterior / posterior colporrhaphy with Kelly's plication (VH$\mathrm{KP}$ ), versus vaginal hysterectomy-anterior / posterior colporrhaphy-transobturator tape (VH-TOT) operations on incontinence, quality of life, and sexual functions in patients with POP and concurrent obvious SUI.

\section{MATERIALS AND METHODS}

\section{Study participants}

After obtaining local ethics committee approval, 50 patients who were treated with $\mathrm{VH}-$ -KP or VH-TOT due to POP and concurrent obvious SUI between 2013 and 2017, were evaluated prospectively and consecutively. In the scope of the study, VH-KP was performed in the first 25 patients, and VH-TOT (Unitape $\mathrm{T}^{\circledR}$, Promedon,
Cordoba, Argentina) was performed in the second 25 patients. Age, parity, duration of SUI, and the number of pads used daily were recorded. All patients were evaluated during the preoperative period using physical and gynecologic examinations, complete urine analysis, urine culture, stress and Q-type test, and urodynamics studies. POP was evaluated using the Baden-Walker Halfway System. All patients were selected from similar diagnostic group to create a more homogeneous group. Therefore, only patients with stage 4 POP (4: the maximum possible prolapse) were included in the study.

Patients with POP and concurrent obvious SUI, aged over 18 years with symptoms lasting more than 1 year, who were not willing pregnancy, who did not prefer organ protective methods, and in whom SUI was urodynamically demonstrated after prolapse reduction, were included in the study. Patients with neurogenic bladder, urinary system infection, and history of previous surgery due to POP and urinary incontinence, pelvic radiation history, whose residual urine after prolapse reduction was over $100 \mathrm{~mL}$, and who had stage 1-3 prolapse according to the Baden-Walker Halfway System were excluded. In addition, patients who preferred pubovaginal sling surgery rather than mid-urethral sling surgery were not evaluated in the study.

\section{Efficacy evaluation}

The efficacy of the surgical procedures was compared using the "Urinary Distress Inventory-6 (UDI-6)" and the "Incontinence Impact Questionnaire 7 (IIQ-7)”. Patients completed the UDI-6 and IIQ-7 forms preoperatively and at the postoperative $6^{\text {th }}$ month. Patient's daily pad usage was reexamined in the $6^{\text {th }}$ month, and improvement rates were calculated. Non usage of pads was accepted as subjective cure rate. In addition, sexually active patients in both groups completed "Index of Female Sexual Function (IFSF)" questionnaires. If the total IFSF score was lower than 25, it was accepted as sexual dysfunction (12-14).

\section{SURGICAL TECHNIQUES}

Transobturator tape surgery was performed in accordance with the description of Delorme's, 
vaginal hysterectomies plus anterior / posterior colporrhaphy in accordance with the description of Heaney, and Kelly plication was performed using Howard Kelly's method. A vaginal pack was inserted in the vagina after surgery. Vaginal pack, and urethral catheter were removed on postoperative first day. Urethral catheters remained for several days in patients who had a post-voiding residual urine volume higher than $100 \mathrm{~mL}$. Intraoperative and postoperative complications were recorded.

\section{Statistical analysis}

The statistical package program Statistical Package for the Social Sciences (SPSS) 11 for Windows was used in statistical calculations. Data are described as arithmetic mean and standard deviation. The Chi-square distribution test was used for the calculation of categoric variables, and the Mann-Whitney U test was used for the comparison of means. "p values" lower than 0.05 were accepted as significant.

\section{RESULTS}

Mean age in the VH-KP group was 62.20 \pm 11.23 years, and $65.12 \pm 11.18$ years in the $\mathrm{VH}-$ -TOT group ( $\mathrm{p}=0.460)$. There was no statistically significant differences between the two groups regarding parity, duration of SUI, and the number of daily pad use $(\mathrm{p}=0.322, \mathrm{p}=0.585, \mathrm{p}=0.301$, respectively) (Table-1).
Decreased UDI-6 scores, IIQ-7 scores and daily pad usage, and increased IFSF scores were found statistical significantly in each group, at the postoperative $6^{\text {th }}$ month (Table-2). When we compared the groups for improvement rates, UDI-6 and IIQ-7 scores were observed higher in the VHTOT group, but IIQ-7 scores were not calculated as statistical significantly (69.5\% vs. $63.0 \%, p=0.04$, $67.3 \%$ vs. $57.8 \%, p=0.182$ ). Although subjective cure rates (68\% vs. $64 \%, p=0.765)$, and improvements on the daily pad usage $(88.76 \%$ vs. $85.92 \%$, $\mathrm{p}=0.782$ ) were higher in the VH-TOT group, there was no statistical difference. Eighteen (72\%) patients in both groups were sexually active. It was notable that the rate of patients with IFSF scores $\geq 25$ was higher in VH-KP group at the postoperative $6^{\text {th }}$ month $(\mathrm{p}=0.05)$ (Table-3).

No intraoperative complications were observed in either group. At the postoperative $6^{\text {th }}$ month, 4 (16\%) patients had recurrent SUI in the VH-KP group ( $\mathrm{p}=0.039)$, and vaginal extrusion occurred in $2(8 \%)$ patients in the VH-TOT group $(p=0.153)$.

\section{DISCUSSION}

Sexual dysfunction rates increase in pelvic floor disorders such as POP and SUI, especially in older patients (15). Urinary incontinence is detected in $20-90 \%$ of women with POP, POP is found in 30-70\% of women with UI, and sexual dysfunction is reported in $31-44 \%$ in women with POP and UI (16). Surgical intervention against POP and

Table 1 - Demographic data of the patients and the operations.

\begin{tabular}{lccc}
\hline & VH-KP & VH-TOT & p value \\
\hline Age (year) & $62.20 \pm 11.23$ & $65.12 \pm 11.18$ & 0.460 \\
Parity (n) & $5.08 \pm 2.21$ & $5.76 \pm 2.58$ & 0.322 \\
Incontinence period (year) & $1.76 \pm 1.42$ & $2.12 \pm 1.76$ & 0.585 \\
Pre-operative daily pad usage (n) & $1.92 \pm 0.95$ & $2.24 \pm 1.2$ & 0.310 \\
Post-operative daily pad usage (n) & $0.4 \pm 0.64$ & $0.36 \pm 0.48$ & 0.935 \\
Sexual active patients $(\mathbf{n}, \%)$ & $18(72 \%)$ & $18(72 \%)$ & 1 \\
\hline
\end{tabular}


Table 2 - Improvements on UDI-6, IIQ-7, IFSF scores, and daily pad use, at the postoperative $6^{\text {th }}$ month.

\begin{tabular}{cccc}
\hline & Pre-operative & Post-operative & $p$ value \\
\hline UDI-6 scores & & & $0.001^{*}$ \\
VH-KP & $14.80 \pm 2.5$ & $5.92 \pm 2.85$ & $0.001^{*}$ \\
VH-TOT & $10.60 \pm 5.1$ & $2.68 \pm 1.65$ & \\
IIQ-7 scores & & & $0.001^{*}$ \\
VH-KP & $16.04 \pm 5.01$ & $6.96 \pm 3.45$ & $0.001^{*}$ \\
VH-TOT & $12.84 \pm 3.70$ & $4.36 \pm 0.99$ & \\
Daily pad usage & $1.92 \pm 0.95$ & & $0.001^{*}$ \\
VH-KP & $2.24 \pm 1.92$ & $0.4 \pm 0.12$ & $0.001^{*}$ \\
VH-TOT & & $0.36 \pm 0.09$ & \\
IFSF scores & $13.27 \pm 6.13$ & & $0.001^{*}$ \\
VH-KP & $12.38 \pm 7.63$ & $31.00 \pm 5.69$ & $0.001^{*}$ \\
VH-TOT & & $27.33 \pm 4.80$ & \\
\hline
\end{tabular}

UDI-6 = Urinary Distress Inventory-6; IIQ-7 = Incontinence Impact Questionnaire-7; IFSI = Index of Female Sexual Function; VH-KP = vaginal hysterectomy - anterior/ posterior colporrhaphy with Kelly's plication; VH-TOT = vaginal hysterectomy - anterior/posterior colporrhaphy - transobturator tape

${ }^{*} p$ values lower than 0.05 were accepted as significant.

Table 3 - Improvements on UDI-6, IIQ-7, IFSF scores, and daily pad use, at the postoperative $6^{\text {th }}$ month.

\begin{tabular}{lccc}
\hline & VH-KP & VH-TOT & p value \\
\hline UDI-6 scores (\%) & $63.0 \pm 14.22$ & $69.52 \pm 24.87$ & $0.04^{*}$ \\
IIQ-7 scores (\%) & $57.88 \pm 23.32$ & $67.32 \pm 32.77$ & 0.182 \\
daily pad usage (\%) & $85.92 \pm 21.42$ & $88.76 \pm 16.12$ & 0.782 \\
subjective cure rates (\%) & 64 & $68 \%$ & 0.765 \\
IFSF scores (\%) & $91.17 \pm 17.97$ & $78.72 \pm 30.42$ & 0.226 \\
IFSF scores $\geq \mathbf{2 5}, \mathbf{n}(\%)$ & $16(88.8 \%)$ & $11(61.6 \%)$ & 0.05 \\
\hline
\end{tabular}

UDI-6 = Urinary Distress Inventory-6; IIQ-7 = Incontinence Impact Questionnaire-7; IFSI = Index of Female Sexual Function

${ }^{\star} p$ values lower than 0.05 were accepted as significant.

SUI provides higher rates of cure in incontinence compared with surgery for POP alone (17). In the present study, we performed VH for the treatment of POP, and KP or TOT procedures were additionally performed for SUI. Significant improvement in incontinence symptoms was observed at the postoperative $6^{\text {th }}$ month, on the UDI- 6 scores, IIQ-7 scores, and daily pad usage in both groups $(\mathrm{p}=0.001, \mathrm{p}=0.001, \mathrm{p}=0.001$, respectively).

In a comprehensive meta-analysis that evaluated the effect of POP and UI surgeries on sexual functions, 21 studies were analyzed. Spe- cific sexual symptoms were examined, or questionnaires were used in the evaluation of sexual functions in patients with UI. General sexual symptoms did not change after incontinence surgery in 18 studies ( $\mathrm{n}=1578$ patients), in more than half (55.5\%) of the patients. Sexual symptoms improved in $31.9 \%$ of the patients, and deterioration was reported in $13.1 \%$ of the patients. An analysis of the effects of mid-urethral sling surgeries [TOT, and tension-free vaginal tape (TVT)] on sexual functions in 16 studies comprising 1252 patients revealed that sexual functions 
did not change in 56.7\%, improved in 33.9\%, and worsened in 9.4\%. The meta-analysis emphasized that improvement of sexual functions was 3-fold higher than the worsening of sexual functions with SUI surgery (18). However, in the present study, we observed that sexual function improved in both groups $(\mathrm{p}=0.001, \mathrm{p}=0.001$, respectively). Although it was not statistically significant, improvement in sexual function rates on IFSF questionnaires were found higher in the VH-KP group $(91.1 \%$ vs. $78.7 \%, p=0.226)$. In addition, the patients with IFSF scores $\geq 25$ was higher in VH-KP group at the postoperative $6^{\text {th }}$ month $(p=0.05)$.

In a recent randomized study, Sohbeti $\mathrm{S}$ et al. randomized 60 patients into two groups (TOT vs. anterior colporrhaphy and Kelly's plication) who underwent SUI surgery. The cure rates in the first, $6^{\text {th }}$, and $12^{\text {th }}$ months in the TOT group were $86.7 \%, 80 \%$, and $80 \%$, respectively, and the cure rates in the anterior colporrhaphy with Kelly's plication group were $80 \%, 70 \%$, and $66.7 \%(\mathrm{p}=0.68$, $\mathrm{p}$ $=0.54$, and $p=0.22$, respectively). The authors reported that although there was no significant differences between the two surgical methods for the improvement of UI at the short-term follow-up, these outcomes might change in the long term (19). In the present study, decreased UDI6 scores, IIQ-7 scores and daily pad usage, and increased IFSF scores were found statistical significantly in each group, at the postoperative $6^{\text {th }}$ month. But, VH-TOT group had higher improvement rates, on UDI-6 scores $(69.5 \%$ vs. $63.0 \%$, $\mathrm{p}=0.04)$. According to current guidelines and recent studies, it is a reality that long-term recurrence of SUI will be lower in patients underwent TOT owing to the mesh usage (17).

However, improvements on sexual functions do not show concordance with improvements on SUI after surgical corrections of POP and / or SUI. It was remarkable to observe more recovery in UI symptoms in the VH-TOT group, and greater recovery in sexual functions in the VK-KP group. The finding of no change or deterioration in the sexual function could be due to changes in vaginal anatomy (mucosal damage, vaginal wall elevation, and narrowing), decreased sensation, libido loss, dyspareunia, anor- gasmia, presence of high levels of residual urine, and de novo urgency after surgery $(18,20$, 21). These results demonstrate the drawbacks of the mesh use. A recent meta-analysis by Jha et al. revealed that a significant increase in sexual function and decrease in dyspareunia was reported after POP surgery with conventional tissue repair (22). Mesh erosion / extrusions, which may be detected in $1 \%$ of patients after sling surgery, have a negative effect on sexual functions (18). In a study investigated the female sexual function after TOT, vaginal erosion was reported as $4.9 \%$, de novo urgency as $4.9 \%$, vesico-vaginal fistula as $1.2 \%$, and urinary retention as 3.7\% (23). In our study, vaginal extrusion was detected in $2(8 \%)$ patients who underwent TOT, and mesh excision was performed. Although there was a significant improvement in sexual functions in the VH-KP group, recurrent SUI developed in 4 (16\%) patients at the $6^{\text {th }}$ postoperative month.

There are limited studies comparing effects of surgeries on incontinence, quality of life, and sexual function in patients with POP, and concurrent obvious SUI. Therefore, we believe that the present study will contribute to the current literature. But, our study has certain limitations. The small sample size and short-term postoperative follow-up are the primary limitations. The current findings should be supported by prospective, randomized studies including wider patient series and long-term results.

\section{CONCLUSIONS}

Although the improvement rates of $\mathrm{VH}-$ TOT surgeries are superior to conventional methods for SUI, and quality of life, the negative effects on sexual function are notable. Even though the SUI recurrence rates of TOT surgeries are lower, complications such as vaginal extrusion are known drawbacks associated with mesh usage. Therefore, in addition to treatment success, patients treated with mesh should be informed about its effects on sexual functions and potential complications. In addition, although it is an outdated method, conventional surgical methods such as Kelly's plication may be offered as an option for patients who request native tissue repair. 


\section{CONFLICT OF INTEREST}

\author{
None declared.
}

\section{REFERENCES}

1. Bump RC, Norton PA. Epidemiology and natural history of pelvic floor dysfunction. Obstet Gynecol Clin North Am. 1998;25:723-46.

2. Nygaard I, Bradley C, Brandt D; Women's Health Initiative. Pelvic organ prolapse in older women: prevalence and risk factors. Obstet Gynecol. 2004;104:489-97.

3. Samuelsson EC, Victor FT, Tibblin G, Svärdsudd KF. Signs of genital prolapse in a Swedish population of women 20 to 59 years of age and possible related factors. Am J Obstet Gynecol. 1999;180(2 Pt 1):299-305.

4. Swift SE. The distribution of pelvic organ support in a population of female subjects seen for routine gynecologic health care. Am J Obstet Gynecol. 2000;183:277-85.

5. Filocamo MT, Serati M, Frumenzio E, Li Marzi V, Cattoni E, Champagne $A$, et al. The impact of mid-urethral slings for the treatment of urodynamic stress incontinence on female sexual function: a multicenter prospective study. J Sex Med. 2011;8:2002-8

6. Vierhout ME, Gianotten WL. Mechanisms of urine loss during sexual activity. Eur J Obstet Gynecol Reprod Biol. 1993:52:45-7.

7. Hilton P. Urinary incontinence during sexual intercourse: a common, but rarely volunteered, symptom. $\mathrm{Br} \mathrm{J}$ Obstet Gynaecol. 1988;95:377-81.

8. Rogers GR, Villarreal A, Kammerer-Doak D, Qualls C. Sexual function in women with and without urinary incontinence and/or pelvic organ prolapse. Int Urogynecol J Pelvic Floor Dysfunct. 2001;12:361-5.

9. Moran PA, Dwyer PL, Ziccone SP. Urinary leakage during coitus in women. J Obstet Gynaecol. 1999;19:286-8.

10. Thaweekul Y, Bunyavejchevin S, Wisawasukmongchol W, Santingamkun A. Long term results of anterior colporrhaphy with Kelly plication for the treatment of stress urinary incontinence. J Med Assoc Thai. 2004;87:357-60.

11. Delorme E, Droupy S, de Tayrac R, Delmas V. Transobturator tape (Uratape): a new minimally-invasive procedure to treat female urinary incontinence. Eur Urol. 2004;45:203-7.

12. Rosen R, Brown C, Heiman J, Leiblum S, Meston C, Shabsigh $\mathrm{R}$, et al. The Female Sexual Function Index (FSFI): a multidimensional self-report instrument for the assessment of female sexual function. J Sex Marital Ther. 2000;26:191-208.
13. Alıcı B. Değerlendirme ve Tanı. In: Kadıoğlu A, Başar M. Erkek ve Kadın Cinsel Sağlığı, İstanbul: Türk Androloji Derneği Yayını. 2004; 630-4.

14. Oksuz E, Malhan S. Prevalence and risk factors for female sexual dysfunction in Turkish women. J Urol. 2006;175:654-8.

15. Shifren JL, Monz BU, Russo PA, Segreti A, Johannes CB. Sexual problems and distress in United States women: prevalence and correlates. Obstet Gynecol. 2008;112:970-8.

16. Stoutjesdijk JA, Vierhout ME, Spruijt JW, Massolt ET. Does vaginal reconstructive surgery with or without vagina hysterectomy or trachelectomy improve sexual well being? A prospective follow-up study. Int Urogynecol J Pelvic Floor Dysfunct. 2006;17:131-5.

17. Burkhard FC, Bosch JLHR, Cruz F, Nambiar AK, Thiruchelvam $\mathrm{N}$, Tubaro $\mathrm{A}$, et al. EAU guidelines on urinary incontinence in adults. European Association of Urology. 2017; 39-48.

18. Jha S, Ammenbal M, Metwally M. Impact of incontinence surgery on sexual function: a systematic review and metaanalysis. J Sex Med. 2012;9:34-43.

19. Sohbati S, Salari Z, Eftekhari N. Comparison Between the Transobturator Tape Procedure and Anterior Colporrhaphy With the Kelly's Plication in the Treatment of Stress Urinary Incontinence: a Randomized Clinical Trial. Nephrourol Mon. 2015; 7:e32046

20. Rogers RG. Sexual function in women with pelvic floor disorders. Can Urol Assoc J. 2013;7(9-10 Suppl 4):S199201.

21. Katz A. Sexuality after hysterectomy: a review of the literature and discussion of nurses' role. J Adv Nurs. 2003;42:297303.

22. Jha S, Gray T. A systematic review and meta-analysis of the impact of native tissue repair for pelvic organ prolapse on sexual function. Int Urogynecol J. 2015;26:321-7.

23. Simsek A, Ozgor F, Yuksel B, Kucuktopcu 0, Kirecci SL, Toptas M, et al. Female sexual function after transobturator tape in women with urodynamic stress urinary incontinence. Springerplus. 2014;3:570.

\footnotetext{
Correspondence address: Omer Bayrak, MD, PhD Department of Urology University of Gaziantep, Gaziantep Turkey 27310, Gazıantep, Turkey Fax: + 90342 360-3998

E-mail: Dromerbayrak@yahoo.com
} 